\title{
A Method to Encapsulate Small Organic Molecules in Calcium Phosphate Nanoparticles Based on the Supramolecular Chemistry of Cyclodextrin
}

\author{
Zhongming Zhu ${ }^{1,+}$, Feng Li $^{2,+}$, Fei Zhong ${ }^{3, *}$, Kang Zhai ${ }^{4}$, Wei Tao ${ }^{4}$ and Gengyun Sun ${ }^{1, *}$ \\ 1 Pulmonary Department, First Affiliated Hospital of Anhui Medical University, Hefei 230022, China; \\ zhuzhongming@ahmu.edu.cn \\ 2 Department of respiration, Shanghai Public Health Clinical Center, Fudan University, Shanghai 201508, \\ China; lifeng@shaphc.org \\ 3 Department of Oncology, Fuyang Hospital of Anhui Medical University, Fuyang 236000, China \\ 4 School of Biological and Medical Engineering, Hefei University of Technology, Hefei 230009, China; \\ zkhj19931015@gmail.com (K.Z.); taow@hfut.edu.cn (W.T.) \\ * Correspondence: Zhong_fei@126.com (F.Z.); sungengy@126.com (G.S.) \\ + These authors contribute equally to this work.
}

Received: 3 September 2017; Accepted: 19 September 2017; Published: 27 September 2017

\begin{abstract}
Calcium phosphate nanoparticles (CPNPs) encapsulating small organic molecules, such as imaging agents and drugs, are considered to be ideal devices for cancer diagnosis or therapy. However, it is generally difficult to encapsulate small organic molecules in CPNPs because of the lack of solubility in water or binding affinity to calcium phosphate. To solve these issues, we utilized the carboxymethyl $\beta$-cyclodextrin (CM- $\beta$-CD) to increase the solubility and binding affinity to small organic molecules for the encapsulation into CPNPs in this work. The results indicated that the model molecules, hydrophilic rhodamine B (RB) and hydrophobic docetaxel (Dtxl), are successfully encapsulated into CPNPs with the assistance of CM- $\beta$-CD. We also demonstrated the CPNPs could be remarkably internalized into A549 cells, resulting in the efficient inhibition of tumor cells' growth.
\end{abstract}

Keywords: calcium phosphate nanoparticles; supramolecular chemistry; cyclodextrin; small organic drug delivery

\section{Introduction}

An ideal carrier for delivering bioactive agents should have several features, including biocompatibility, safety, and controlled drug release [1-3]. Calcium phosphate (CaP), the major component of human bones and teeth, is highly biocompatible, and relatively insoluble at a $\mathrm{pH}$ above 7.4, but dissolves into calcium and phosphate ions at a $\mathrm{pH}$ below 6 . When bioactive agents are encapsulated in nano-sized Calcium phosphates ( $\mathrm{CaPs})$, they will be protected from the outer environment and prevented from undesired release to normal tissues or cells during circulation $(\sim \mathrm{pH} 7.4)$; after accumulating in solid tumor tissue and internalizing into tumor cells, these agents are finally released in endosomes ( $\mathrm{pH} \sim 5.4$ ) or lysosomes ( $\mathrm{pH} \sim 4.5)$. Therefore, calcium phosphate nanoparticles (CPNPs) have been considered one of the most promising delivery devices for cancer diagnosis or therapy [4-6].

Various nuclei acids [7-9], proteins [10-12], or polysaccharides [13-15] have been encapsulated into CPNPs based on a precipitation reaction of the CaPs in water with the presence of these biomacromolecules. However, it is difficult to encapsulate small hydrophobic organic molecules in $\mathrm{CPNP}$ because the preparation of $\mathrm{CaP}$ is performed in water, while the hydrophobic organic molecule was insoluble during the preparation [16]. Additionally, the binding affinity of these molecules to $\mathrm{CaP}$ should be strong enough to ensure the efficient encapsulation [17-19]. Two strategies have been 
developed to encapsulate small organic molecules into CPNPs. The first strategy, pioneered by Adair and co-workers, is preparing the CPNPs by a double reverse emulsion procedure using disodium silicate as a nucleation agent [20-22]. However, this method is limited by the solubility of the molecules and the addition of organic solvents $[4,16]$. The other strategy is using assistant nanoparticles for the simultaneous functions of encapsulating and binding, such as polymeric self-assemblies [23-28], liposomes [29], mesoporous silica [30], or even viruses [31] and cells [32]. However, the preparation of these assistant nanoparticles often requires sophisticated skills.

Cyclodextrins (CDs) are cyclic oligosaccharides with the ability to form complexes with a wide spectrum of drug molecules via noncovalent interactions in their hydrophobic cavities [33,34], and the hydroxy groups around their rims can be modified to endow strong binding ability to $\mathrm{CaP}[35,36]$. $\mathrm{CDs}$ and their derivatives have been widely used to improve the performance of bulk CaPs [37] or to decorate the surfaces of CPNPs [38]. Recently, Raj and co-workers synthesized CPNPs using $\beta$-CD as a medium to conjugate rhodamine isocyanide for $\mathrm{H}_{2} \mathrm{O}_{2}$ detection [39]. Inspired by these studies, we proposed a facile method to encapsulate small organic molecules into CPNPs with the assistant of CDs (Figure 1). We prepared carboxymethyl $\beta$-cyclodextrin (CM- $\beta-C D)$ to afford the functions of encapsulating cargo molecules and binding to $\mathrm{CaP}$ crystallites simultaneously. When $\mathrm{CM}-\beta-\mathrm{CD}$ forms noncovalent complexes with small organic molecules, it not only improves their solubility but also forms CaPs occurring around the host-guest pairs through interactions between carboxy groups and CaPs. We chose rhodamine B (RB) and docetaxel (Dtxl) as model molecules to represent hydrophilic and hydrophobic molecules, respectively. The results indicated that RBs and Dtxls could be efficiently encapsulated into CPNPs with the assistance of CM- $\beta$-CD.

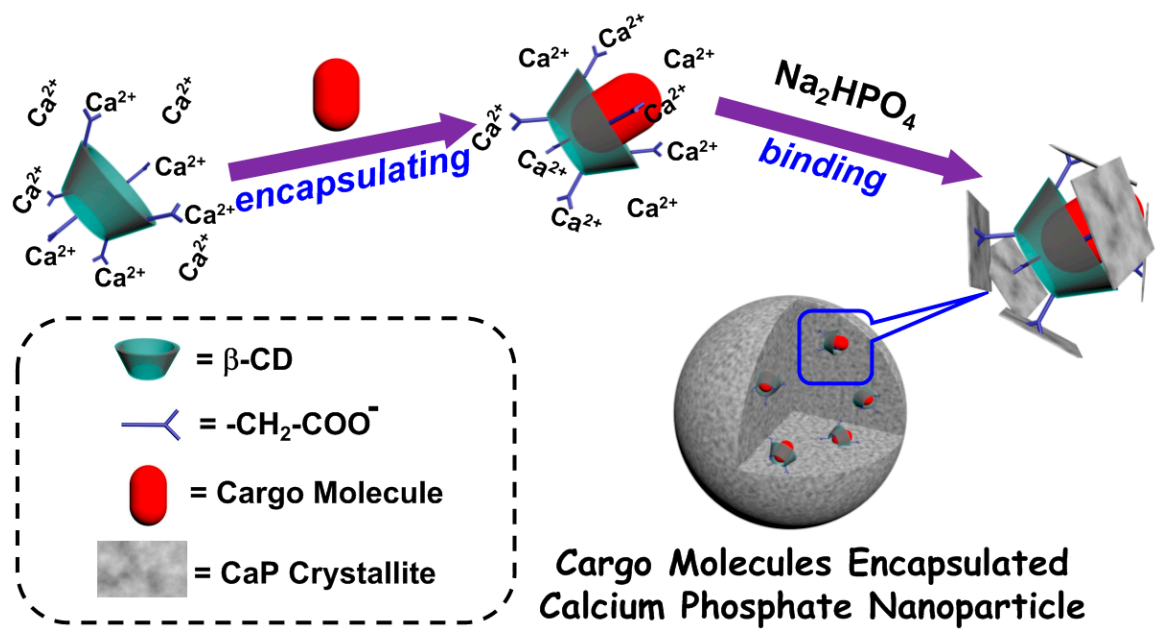

Figure 1. Illustration of the functions of $C M-\beta-C D$ in preparation of cargo molecules encapsulated calcium phosphate nanoparticles.

\section{Materials and Methods}

\subsection{Materials and Characterization}

Calcium chloride $\left(\mathrm{CaCl}_{2}\right)$, disodium hydrogen phosphate $\left(\mathrm{Na}_{2} \mathrm{HPO}_{4}\right), \beta$-cyclodextrin $(\beta-\mathrm{CD})$, sodium citrate, sodium hydroxide $(\mathrm{NaOH})$, concentrated hydrochloric acid $(\mathrm{HCl}, 36.5 \%)$, chloroacetic acid, and ethanol were purchased from Sinopharm Chemical Reagent Co., Ltd. (Shanghai, China). Rhodamine B (RB) and docetaxel (Dtxl) were purchased from Shanghai Aladin Co., Ltd. (Shanghai, China). Dimethyl sulfoxide (DMSO) and [3-(4,5-dimethylthiazol-2-yl)-2 and 5-diphenyltetrazolium bromide] (MTT) were purchased from Sigma-Aldrich (St. Louis, MO, USA). All reagents were of analytical grade and used as received. 
Dynamic Light Scattering (DLS) measurements were performed under a Malvern Instruments Zetasizer Nano series instrument (ZS90, Malvern, Worcestershire, UK) equipped with a $22 \mathrm{~mW}$ laser light and operating at a wavelength of $633 \mathrm{~nm}$. All samples were about $1 \mathrm{mg} / \mathrm{mL}$ and measured at $25^{\circ} \mathrm{C}$ with a scattering angle of $90^{\circ}$. Transmission electron microscopy (TEM) measurements were performed with an H-800 electron microscope (Hitachi, Tokyo, Japan). The ultraviolet-visible (UV-Vis) absorbance experiments were performed with a UV-7504 spectrophotometer (Shanghai Xinmao Ltd., Shanghai, China). High-performance liquid chromatography (HPLC) was performed on a HP1100 (Agilent, Oshawa, ON, Canada) system with an Atlantis column as stationary phase at $25^{\circ} \mathrm{C}$. A mixture of acetonitrile and water (55:45) was used as mobile phase at a flow rate of $1 \mathrm{~mL} / \mathrm{min}$. Detection was performed with a diode-array detector at a detection wavelength of $230 \mathrm{~nm}$.

\subsection{Synthesis of RBs-Encapsulated CPNPS (RBs-en-CPNPS)}

To a mixture of CM-b-CD (20 mg) and RBs ( $8 \mathrm{mg})$ in an aqueous solution of $\mathrm{CaCl}_{2}(20 \mathrm{~mL}, 0.04 \mathrm{M})$, $\mathrm{Na}_{2} \mathrm{HPO}_{4}$ in water $(12 \mathrm{~mL}, 0.04 \mathrm{M})$ was added dropwise within $30 \mathrm{~min}$. Subsequently, the mixture was adjusted to $\mathrm{pH} 10$ by an aqueous solution of $\mathrm{NaOH}(1 \mathrm{M})$ and stirred for $1 \mathrm{~h}$. Then, $30 \mathrm{mg}$ of sodium citrate was added. After further stirring for $1 \mathrm{~h}$, the mixture was dialyzed against (MWCO: $3500 \mathrm{Da}$ ) water for $24 \mathrm{~h}$. Then, the mixture was centrifuged at 10,000 r/m for $15 \mathrm{~min}$, and the obtained precipitate was re-dispersed in ethanol, centrifuged at 10,000 r/m for $15 \mathrm{~min}$ to remove the residual RBs three times. The final product was collected and dried at $40{ }^{\circ} \mathrm{C}$ under a vacuum.

To investigate if the RBs can be encapsulated into CaPs directly, we prepared CaPs in the aqueous solution of RBs. The synthesis process was as same as the one for RBs-en-CPNPs, except that CM-b-CD was absent. Moreover, we also prepared the CaPs, and then the RBs and CM-b-CD was added. The obtained formulation was used as a control.

\subsection{Synthesis of Dtxls-Encapsulated CPNPS ((Dtxls-en-CPNPS))}

Briefly, $25 \mathrm{mg}$ of CM-b-CD and $2.5 \mathrm{mg}$ of Dtxls were added to an aqueous solution of $\mathrm{CaCl}_{2}$ $(20 \mathrm{~mL}, 0.04 \mathrm{M})$. After ultrasonication for $1 \mathrm{~h}$, an aqueous solution of $\mathrm{Na}_{2} \mathrm{HPO}_{4}(12 \mathrm{~mL}, 0.04 \mathrm{M})$ was added dropwise within $30 \mathrm{~min}$. Then, the mixture was adjusted to $\mathrm{pH} 10$ by an aqueous solution of $\mathrm{NaOH}(1 \mathrm{M})$ and stirred for $1 \mathrm{~h}$. Subsequently, $30 \mathrm{mg}$ of sodium citrate was added, stirred for an additional $1 \mathrm{~h}$, and then transfer into dialysis bag (MWCO: $3500 \mathrm{Da}$ ) and dialysis against water for $24 \mathrm{~h}$. Then, the mixture was centrifuged at $10,000 \mathrm{r} / \mathrm{m}$ for $15 \mathrm{~min}$. The obtained precipitate was re-dispersed in ethanol and then centrifuged at $10,000 \mathrm{r} / \mathrm{m}$ for $15 \mathrm{~min}$ to remove residual Dtxls. The final product was collected and dried at $40{ }^{\circ} \mathrm{C}$ under vacuum. Moreover, we also prepared the control formulation; the Dtxls was added the previously formed CaPs. Blank CPNPs were prepared by the similar synthesis process, except that Dtxls were absent.

\subsection{Calculation of Loading Content and Loading Efficiency}

The loading efficiency (LE) and loading content (LC) were calculated according to the equations:

$$
\begin{gathered}
\mathrm{LE} \%=\frac{\text { Weight of drug found loaded }}{\text { Weight of drug input }} \times 100 \% \\
\mathrm{LC} \%=\frac{\text { Weight of drug found loaded }}{\text { Weight of drug loaded nanoparticles }} \times 100 \% .
\end{gathered}
$$

Briefly, $12 \mathrm{mg}$ of RBs-en-CPNPs were added to $10 \mathrm{~mL}$ of $\mathrm{HCl}$ solution ( $\mathrm{pH} 1)$. The mixture was treated by ultrasonication for at least $30 \mathrm{~min}$, then lyophilized to remove water. After that, $10 \mathrm{~mL}$ of PBS ( $\mathrm{pH}$ 5.4) was added and then measured by UV spectrophotometry at a wavelength of $555.7 \mathrm{~nm}$. The quantity was calculated according to the standard curve of UV absorbance intensities to concentrations of RBs. 
For Dtxls-en-CPNPs, $5 \mathrm{mg}$ of Dtxls-encapsulated CPNPs were added to $5 \mathrm{~mL}$ of $\mathrm{HCl}$ solution (pH: 1). The mixture was treated by ultrasonication for $30 \mathrm{~min}$, then lyophilized to remove water. After that, $10 \mathrm{~mL}$ of methanol was added. The mixture was treated by a vortex mixer for $10 \mathrm{~min}$, centrifuged for $10 \mathrm{~min}$ at 10,000 rmp, and then $20 \mu \mathrm{L}$ of supernatant was measured by HPLC with acetonitrile/water $(55: 45, v / v)$ as eluent.

\subsection{Cargo Release}

Forty milligrams of cargo molecule encapsulated CPNPs were added into $20 \mathrm{~mL}$ PBS solution ( $\mathrm{pH} 5.4$ or 7.4), then the mixture was transferred to a dialysis bag (MWCO: $3500 \mathrm{Da}$ ). After the dialysis bag was immersed in $200 \mathrm{~mL}$ of corresponding PBS solution, the release was performed in a thermostatic shaker $\left(37^{\circ} \mathrm{C}, 150 \mathrm{rpm}\right)$. At predetermined intervals, $2.0 \mathrm{~mL}$ buffer solution outside the dialysis bag was extracted and it was replaced by an equal volume of fresh media to keep the thermostatic shaker. The amount of released cargo molecules was analyzed by UV absorbance (RBs) or HPLC (Dtxl).

\subsection{Cell Culture}

The human lung cancer cell line A549 (ATCC) (Shanghai Fumengiiyin Biotechnology Co., Ltd., Shanghai, China) were cultured in DMEM (Gibco, Carlsbad, CA, USA) with 10\% fetal bovine serum (Gibco) at $37^{\circ} \mathrm{C}$ with $5 \% \mathrm{CO}_{2}$ humidified atmosphere.

\subsection{Flow Cytometry}

A549 cells were seeded into six-well plates at $1 \times 10^{5}$ cells per well in $0.5 \mathrm{~mL}$ of complete DMEM medium and cultured at $37^{\circ} \mathrm{C}$ in a $5 \% \mathrm{CO}_{2}$ humidified atmosphere for $24 \mathrm{~h}$. The medium was replaced with DMEM medium containing RBs-en-CPNPs at a RBs dose of $20 \mathrm{mM}$. The cells were incubated at $37^{\circ} \mathrm{C}$ for $1 \mathrm{~h}, 2 \mathrm{~h}$, or $4 \mathrm{~h}$, and then the cells were rinsed, trypsinized, and subjected to flow cytometric analysis using a BD FACSCalibur flow cytometer (BD Bioscience, Bedford, MA, USA).

\subsection{Confocal Microscopy}

A549 cells were incubated with RBs-en-CPNPs at a RBs dose of $20 \mathrm{mM}$ for $1 \mathrm{~h}, 2 \mathrm{~h}$, or $4 \mathrm{~h}$, and then washed twice with PBS, and fixed with $4 \%$ formaldehyde for $15 \mathrm{~min}$ at room temperature. The cell cytoskeleton F-actin and cell nuclei were counterstained with Alexa Fluor 488 and DAPI respectively. Coverslips were mounted on glass microscope slides with a drop of anti-fade mounting media (Sigma-Aldrich) to reduce fluorescence photobleaching. The cellular uptake of RBs-en-CPNPs was visualized by a confocal laser scanning microscope (LSM 710, Carl Zeiss Inc., Jena, Germany).

\subsection{Cytotoxicity Assay}

The cytotoxicity of Dtxl-en-CPNPs was measured by MTT test. Typically, A549 cells were cultured in 96-well plates at a density of $1.0 \times 10^{4}$ cells per well. Subsequently, serial dilutions of CPNPs were added. After incubation for $48 \mathrm{~h}$, the samples were treated with MTT for $4 \mathrm{~h}$. The formed formazan crystals were then dissolved in DMSO and absorbance was measured at $570 \mathrm{~nm}$ on a microplate reader (Model 680; Bio-Rad, Hercules, CA, USA).

\section{Results and Discussion}

\subsection{Synthesis of Small Organic Molecule Encapsulated CPNPS}

In this work, the CPNPs were firstly synthesized by the simple precipitation reaction of $\mathrm{CaCl}_{2}$ and $\mathrm{Na}_{2} \mathrm{HPO}_{4}$ in water with RBs or Dtxls, then stabilized by sodium citrate, and finally laundered by dialysis against water and subsequent washing with ethanol. However, only withe powder was obtained after laundering process (Figure 2a). The loading content (LC) and loading efficiency (LE) of 
RB were ca. $0.0140 \%$ and $1.28 \%$, respectively, indicating that RB could barely be encapsulated directly into CaPs.

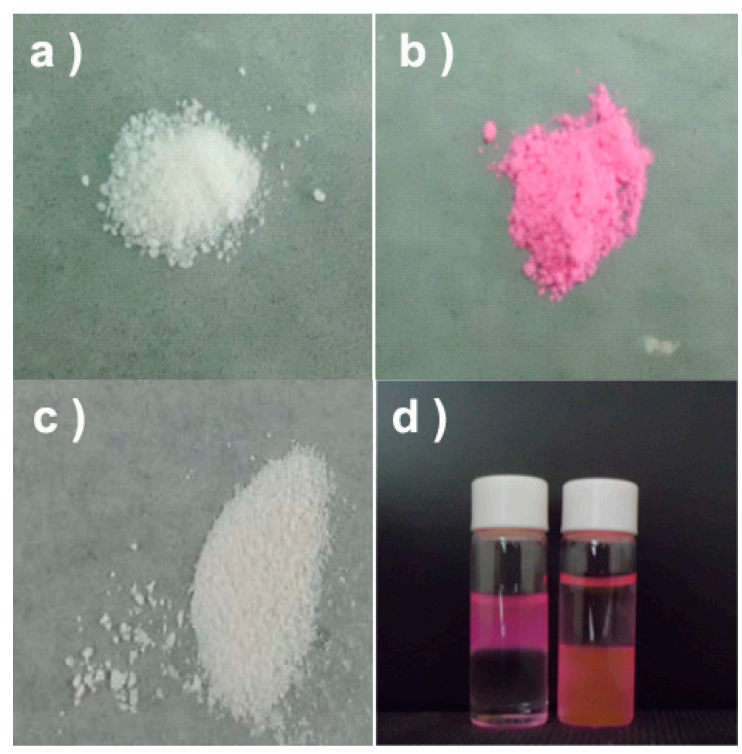

Figure 2. (a-c) The photographs of the CaPs synthesized in the solutions of RBs (a) without, (b) with the CM-b-CD and (c) by adding the solution of RBs and CM-b-CD after the CaPs formed; (d) the imagine of the RBs encapsulated CaPs in the water (upper layer)/chloroform (bottom layer) system before (left bottle) and after (right bottle) concentrated $\mathrm{HCl}$ was added.

$\mathrm{CD}$ or $\mathrm{CD}$ derivatives are able to accommodate the lactone group of RB's lactone form or the diethylaminophenyl group of its carboxylate ion form in their cavities [40]. Thus, the CM-b-CD was synthesized by reaction of $\mathrm{b}-\mathrm{CD}$ and chloroacetic acid under alkaline condition, and ${ }^{1} \mathrm{H}$ NMR indicated that the carboxymethyl groups were grafted on the rim of b-CD with the substitution number about 6 (ESI, Figure S1). Subsequently, the formation of supramolecular complex between RB and CM-b-CD was investigated. The result of 2D NOESY spectroscopy revealed that RB and CM-b-CD were able to form complex in the condition for preparing CaPs with the latter mode (ESI, Figure S2). When $\mathrm{CaPs}$ were synthesized in the aqueous solution of RBs in the presence of $C M-b-C D$, pink powder was obtained after laundering process (Figure $2 b$ ). UV-vis absorbance experiments further indicated that absorbance of RB in PBS was not affected by addition of CM-b-CD (ESI, Figure S3), neither in $\mathrm{pH} 7.4$ nor $\mathrm{pH}$ 5.4. Therefore, the LC and LE of RB, which were calculated according to UV-vis absorbance, were $0.82 \%$ and $32.72 \%$, respectively. Changing the feeding order can be used to estimate if the interested materials are encapsulated [41], therefore, we synthesized another control sample by adding the mixture of RBs and CM-b-CD after the formation of CaPs. The product was a white powder (Figure 2c), and the LC and LE of RBs $0.0037 \%$ and $0.012 \%$, respectively. This result indicated that $\mathrm{CM}-\mathrm{b}-\mathrm{CD}$ would not assist RBs anchoring on the surface of $\mathrm{CaPs}$. Furthermore, to corroborate the encapsulated feature of the RBs and the $\mathrm{pH}$-sensitive property of the CaPs, extraction experiments were operated. As shown in Figure 2d, the RBs, carried by the pink powder, were stable in water phase and extracted into chloroform (Figure 2d, left bottle). However, after being added several drops of concentrated $\mathrm{HCl}$, the upper aqueous phase became transparent, and the RBs transported to the chloroform phase almost entirely (Figure 2d, right bottle). Because RBs cannot bind to the surface of CaPs tightly, the extraction experiments proved that the RBs were incorporated inside CaPs and acidic conditions would make them exposed.

Dtxl cannot be encapsulated in CPNP directly because of its poor solubility in water. When $\mathrm{CM}-\mathrm{b}-\mathrm{CD}$ was added into the suspension of Dtxls in $\mathrm{CaCl}_{2}$ solution, the formation of a transparent solution indicated the supramolecular complexes formed, which were further verified by 2D NOESY 
experiment (ESI, Figure S4). After an analogous synthesis procedure to the one for RBs encapsulated CaPs, the Dtxls-loaded CaPs were obtained. The quantity of Dtxls-loaded CaPs was characterized with HPLC [42]. The LC and LE were 6.24\% and 36.25\%, respectively. However, when the solution of Dtxls and CM-b-CD was added after the formation of CaPs, the LC and LE were only 0.11 wt \% and $3.34 \mathrm{wt} \%$, respectively, implying that the Dtxls must added during the formation of CaPs.

To investigate the size of the cargo molecule-encapsulated CaPs, DLS and TEM were used. The diameters of the RBs-en-CaPs observed by DLS were about $100 \mathrm{~nm}$ (Figure 3a), which coincided with the observation from TEM (Figure 3b). On the contrary, the diameters of the Dtxls-en-CaPs increased to $200 \mathrm{~nm}$ by DLS (Figure 3c), which was further confirmed by TEM (Figure 3d). These results for the RBs-en-CPNPs and Dtxls-en-CPNPs were successfully synthesized with the assistance of CM-b-CD. Additionally, the stability of RBs-en-CPNPs and Dtxls-en-CPNPs was also detected [43]. As shown in Figure S5, the sizes showed almost no increase in PBS containing 10\% FBS, exhibiting excellent stability.
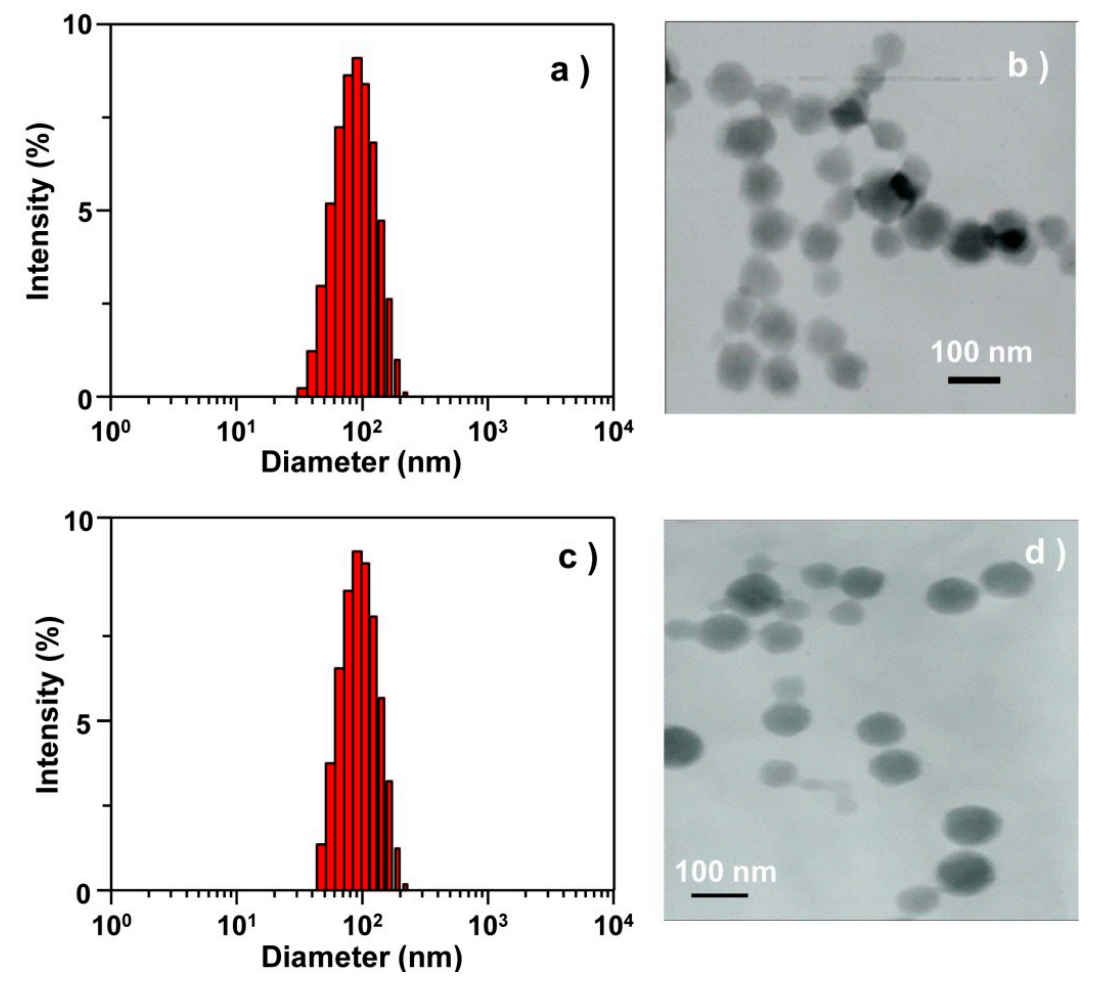

Figure 3. (a,c) Intensity distributions of the sizes of (a) RB and (c) Dtxls encapsulated CaPs; (b,d) TEM images of (b) RB and (d) Dtxls-encapsulated CaPs.

\subsection{In Vitro Release of the Cargo Molecules from CPNPs}

CPNPs are a kind of smart vehicle because of its $\mathrm{pH}$ dependent solubility. To demonstrate it, the release profiles of RBs-en-CaPs and Dtxls-en-CaPs at pH 7.4 and 5.4 were analyzed. For the RBs-en-CaPs (Figure 4a), there were nearly no release of RBs at $\mathrm{pH} 7.4$, while the RBs were almost entirely released within $40 \mathrm{~h}$ at $\mathrm{pH}$ 5.4, implying that the CPNPs was able to prevent the release of the cargoes during circulation and then release them after the nanoparticles enter into an acidic endosome/lysosome. For Dtxls-en-CaPs (Figure 4b), a similar release profile was observed. However, to achieve complete release, the time for Dtxls-en-CaPs was about three times that of RBs-en-CaPs. We supposed this phenomenon might be caused by two reasons: one is that the dimeter of Dtxls-en-CPNPs was about double that of RBs-en-CPNPs, and the larger superficial area of the RBs-en-CPNPs meant RBs were exposed more quickly under acidic conditions; the other is that the diffusion of the Dtxls in water might be slower because of their hydrophobic nature. 

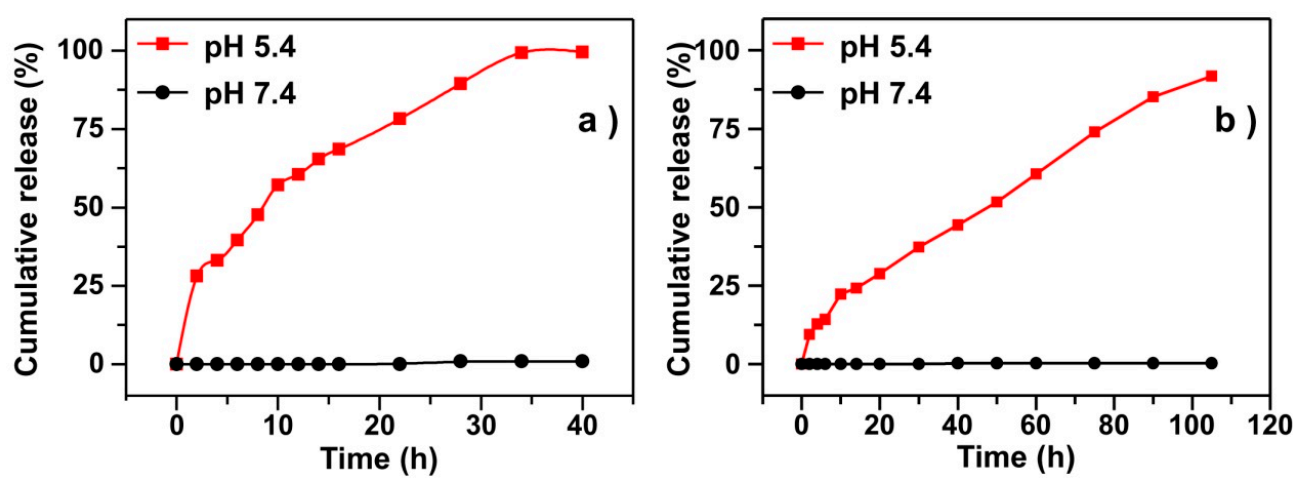

Figure 4. Release profiles of (a) RBs and (b) Dtxls from the corresponding CPNPs at pH 7.4 and 5.4.

\subsection{Cellular Uptake of the CPNPS}

As reported, the nanoparticles can be internalized into tumor cells via the endocytosis pathway [44]. To observe the cell internalization of the CPNPs, RBs-en-CPNPs were used for flow cytometry analyses because of the fluorescent property of RB. A549 cells were incubated with RBs-en-CPNPs at a RBs dose of $20 \mathrm{mM}$. After incubation for different times, the intracellular RBs' fluorescence was determined by flow cytometric analysis. As shown in Figure 5, the strong intracellular fluorescence of A549 cells was detected, indicating that the CPNPs were internalized by the cells. Meanwhile, the fluorescence intensity of the cells increased with the extension of culturing time from $1 \mathrm{~h}$ to $4 \mathrm{~h}$, indicating continual cellular uptake.

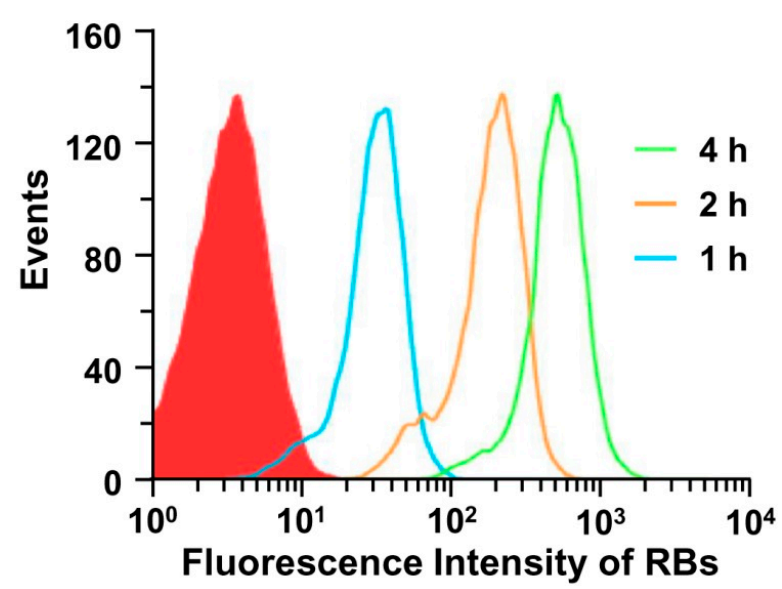

Figure 5. Flow cytometry analyses of the cellular uptake of RBs-en-CPNPs.

Furthermore, confocal laser scanning microscopy (CLSM) analysis was further used to evaluate the cellular uptake of the CPNPs. A549 cells were incubated with RBs-en-CPNPs at an RBs dose of $20 \mathrm{mM}$. After incubation for different times, the cytoskeleton F-actin and the cell nuclei were counter-stained with Alexa Fluor 488 and DAPI, respectively. As shown in Figure 6, the red color around the cell nuclei was clearly observed, which further confirmed the efficient cellular uptake of RBs-en-CPNPs. Additionally, it was demonstrated that the fluorescence intensity of cells incubated with RBs-en-CPNPs increased with the extension of culturing time, which was consistent with the results of flow cytometry analyses. 


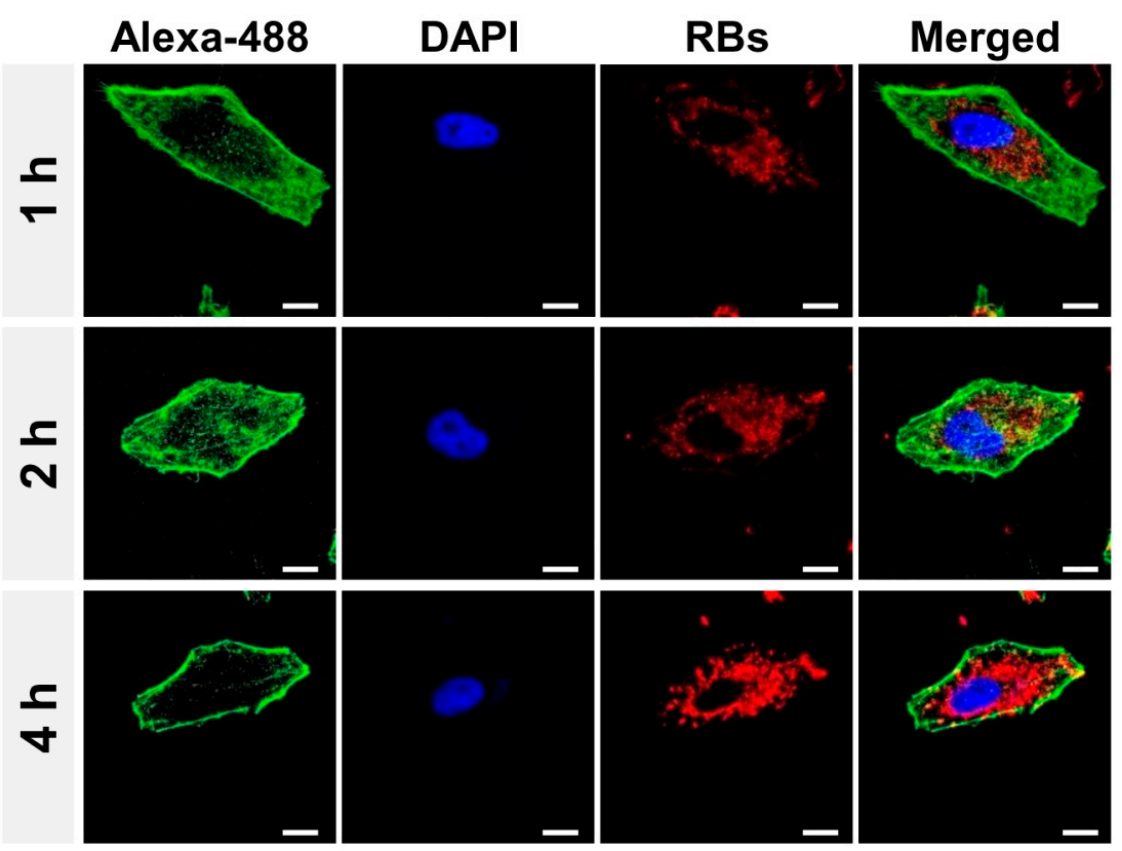

Figure 6. Confocal laser scanning microscopy observation of A549 cells incubated with RBs-en-CPNPs. The red fluorescence represented the intracellular RBs signal. Cell nuclei and the cytoskeleton were stained with DAPI (Blue) and Alexa Fluor 488 phalloidin (Green), respectively. Scale bar $=10 \mu \mathrm{m}$.

\subsection{Cell Cytotoxicity}

As an anticancer drug, Dtxl can induce apoptosis by binding tubulin to promote polymerization and prevent the depolymerization of microtubules causing mitotic arrest [45]. To evaluate the anticancer efficacy of the Dtxls-en-CPNPs, an MTT test was performed. Additionally, blank CPNPs were used as a control. As shown in Figure 7, blank CPNPs showed almost no cytotoxicity to A549 cells (red line), indicating their good biocompatibility. However, the Dtxls-en-CPNPs greatly increased the death rate of $\mathrm{A} 549$ cells with the $\mathrm{IC}_{50}$ at about $0.037 \mathrm{mM}$, exhibiting clear activity against tumor cells.

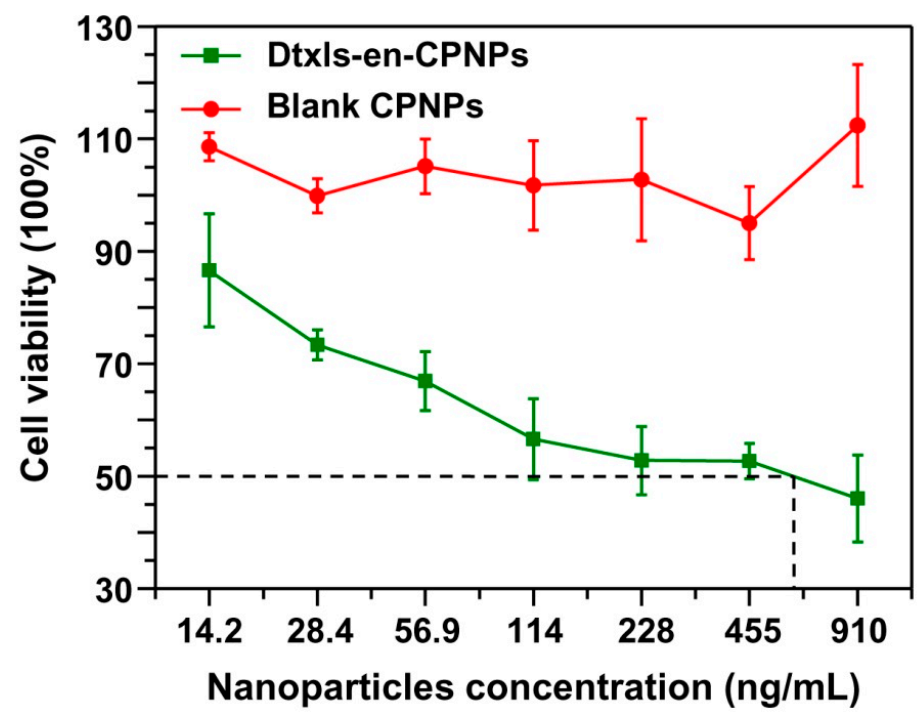

Figure 7. In vitro cytotoxicity profile of blank CPNPs and Dtxls-en-CPNPs against A549 cells. 


\section{Conclusions}

In summary, we have proposed a facile method to prepare small organic molecules encapsulated CPNPs based on the supramolecular chemistry of cyclodextrins. CM- $\beta-C D$ was used to afford the functions of improving the solubility of cargo molecules and binding affinity to CaP. Two model molecules, a hydrophilic dye (RB) with a lack of binding affinity to $\mathrm{CaP}$ and a hydrophobic anticancer drug (Dtxl) unable to dissolve in water, were able to be encapsulated in CPNPs efficiently with the assistance of $C M-\beta-C D$. Furthermore, the functional studies demonstrated the potential applications of the CPNPs as bioimaging or anticancer devices. Encouraged by in vitro results, we will carry out in vivo animal experiments to further study the biodistribution and anticancer efficacy of the CPNPs.

Supplementary Materials: The following are available online at www.mdpi.com/2072-666X/8/10/291/s1, Figure S1: ${ }^{1} \mathrm{H}$ NMR of CM- $\beta-C D$, Figure S2: (A) 2 D NOESY spectrum of CM- $\beta-C D\left(8.4 \times 10^{-4} \mathrm{M}\right)$ and RB $\left(6.7 \times 10^{-4} \mathrm{M}\right)$ in $\mathrm{CaCl}_{2}$ solution $(0.04 \mathrm{M})$ of $\mathrm{D}_{2} \mathrm{O}$ and $(\mathrm{B})$ the illustration of the interaction mode between $\mathrm{CM}-\beta-\mathrm{CD}$ and RB, Figure S3: UV-Vis absorbance spectra of RB with the addition of CM- $\beta-C D$ in PBS solution at pH (A) 7.4 and (B) 5.4, Figure S4: 2D NOESY spectrum of CM- $\beta$-CD $\left(1.5 \times 10^{-4} \mathrm{M}\right)$ and $\mathrm{RB}\left(8.4 \times 10^{-4} \mathrm{M}\right)$ in $\mathrm{CaCl}_{2}$ solution $(0.04 \mathrm{M})$ in $\mathrm{D}_{2} \mathrm{O}$, Figure S5: The size change of RBs-en-CPNPs Dtxls-en-CPNPs following incubation with PBS containing $10 \%$ FBS.

Acknowledgments: This work was supported by the National Natural Science Foundation of China (21304028). Sincere thanks are given to Jianxun Ding from Changchun Institute of Applied Chemistry, Chinese Academy of Sciences for reviewing and editing the manuscript.

Author Contributions: Zhongming Zhu, Feng Li, Fei Zhong, and Gengyun Sun conceived and designed the experiments; Zhongming Zhu, Feng Li, Fei Zhong, Kang Zhai, Wei Tao, and Gengyun Sun performed the experiments and analyzed the data; Zhongming Zhu, Fei Zhong, and Gengyun Sun wrote the paper.

Conflicts of Interest: The authors declare no competing financial interest.

\section{References}

1. Loh, X.J.; Barrio, J.D.; Toh, P.P.C.; Lee, T.C.; Jiao, D.; Rauwald, U.; Appel, E.A.; Scherman, O.A. Triply Triggered Doxorubicin Release from Supramolecular Nanocontainers. Biomacromolecules 2012, 13, 84-91. [CrossRef] [PubMed]

2. Adair, J.H.; Parette, M.P.; Altinoglu, E.I.; Kester, M. Nanoparticulate Alternatives for Drug Delivery. ACS Nano 2010, 4, 4967-4970. [CrossRef] [PubMed]

3. Gao, M.; Fan, F.; Li, D.; Yu, Y.; Mao, K.; Sun, T.; Qian, H.; Tao, W.; Yang, X. Tumor acidity-activatable TAT targeted nanomedicine for enlarged fluorescence/magnetic resonance imaging-guided photodynamic therapy. Biomaterials 2017, 133, 165-175. [CrossRef] [PubMed]

4. Zhang, M.; Kataoka, K. Nano-structured composites based on calcium phosphate for cellular delivery of therapeutic and diagnostic agents. Nano Today 2009, 4, 508-517. [CrossRef]

5. Hu, Y.; Haynes, M.T.; Wang, Y.; Liu, F.; Huang, L. A highly efficient synthetic vector: Nonhydrodynamic delivery of DNA to hepatocyte nuclei in vivo. ACS Nano 2013, 7, 5376-5384. [CrossRef] [PubMed]

6. Li, D.; Zhang, G.; Xu, W.; Wang, J.; Wang, Y.; Qiu, L.; Ding, J.; Yang, X. Investigating the effect of chemical structure of conjugated polymer nanoparticle on photothermal therapy and photoacoustic imaging. Theranostics 2017, 7, 4029-4040.

7. Choi, K.Y.; Silvestre, O.F.; Huang, X.; Min, K.H.; Howard, G.P.; Hida, N.; Jin, A.J.; Carvajal, N.; Lee, S.W.; Hong, J.I.; et al. Versatile RNA interference nanoplatform for systemic delivery of RNAs. ACS Nano 2014, 8 , 4559-4570. [CrossRef] [PubMed]

8. Huang, J.L.; Jiang, G.; Song, Q.X.; Gu, X.; Hu, M.; Wang, X.L.; Song, H.H.; Chen, L.P.; Lin, Y.Y.; Jiang, D.; et al. Lipoprotein-biomimetic nanostructure enables efficient targeting delivery of siRNA to Ras-activated glioblastoma cells via macropinocytosis. Nat. Commun. 2017, 8, 15144-15152. [CrossRef] [PubMed]

9. Keles, E.; Song, Y.; Du, D.; Dong, W.J.; Lin, Y.H. Recent progress in nanomaterials for gene delivery applications. Biomater. Sci. 2016, 4, 1291-1309. [CrossRef] [PubMed]

10. Sokolova, V.; Knuschke, T.; Kovtun, A.; Buer, J.; Epple, M.; Westendorf, A.M. The use of calcium phosphate nanoparticles encapsulating Toll-like receptor ligands and the antigen hemagglutinin to induce dendritic cell maturation and T cell activation. Biomaterials 2010, 31, 5627-5633. [CrossRef] [PubMed] 
11. Tada, S.; Chowdhury, E.H.; Cho, C.S.; Akaike, T. pH-sensitive carbonate apatite as an intracellular protein transporter. Biomaterials 2010, 31, 1453-1459. [CrossRef] [PubMed]

12. Zeng, B.; Shi, H.; Liu, Y. A versatile $\mathrm{pH}$-responsive platform for intracellular protein delivery using calcium phosphate nanoparticles. J. Mater. Chem. B 2015, 3, 9115-9121. [CrossRef]

13. Han, S.Y.; Han, H.S.; Lee, S.C.; Kang, Y.M.; Kim, I.S.; Park, J.H. Mineralized hyaluronic acid nanoparticles as a robust drug carrier. J. Mater. Chem. 2011, 21, 7996-8001. [CrossRef]

14. Chen, C.; Zheng, P.; Cao, Z.Y.; Ma, Y.C.; Li, J.; Qian, H.S.; Tao, W.; Yang, X.Z. PEGylated hyperbranched polyphosphoester based nanocarriers for redox-responsive delivery of doxorubicin. Biomater. Sci. 2016, 4, 412-417. [CrossRef] [PubMed]

15. Thambi, T.; Park, J.H.; Lee, D.S. Stimuli-responsive polymersomes for cancer therapy. Biomater. Sci. 2016, 4, 55-69. [CrossRef] [PubMed]

16. TMorgan, T.; Muddana, H.S.; Altinoglu, E.I.; Rouse, S.M.; Tabakovic, A.; Tabouillot, T.; Russin, T.J.; Shanmugavelandy, S.S.; Butler, P.J.; Eklund, P.C.; et al. Encapsulation of organic molecules in calcium phosphate nanocomposite particles for intracellular imaging and drug delivery. Nano Lett. 2008, 8, 4108-4115. [CrossRef] [PubMed]

17. Kaur, S.; Prasad, C.; Balakrishnan, B.; Banerjee, R. Trigger responsive polymeric nanocarriers for cancer therapy. Biomater. Sci. 2016, 3, 955-987. [CrossRef] [PubMed]

18. George, A.; Veis, A. Phosphorylated proteins and control over apatite nucleation, crystal growth, and inhibition. Chem. Rev. 2008, 108, 4670-4693. [CrossRef] [PubMed]

19. Barth, B.M.; Sharma, R.; Altinoglu, E.I.; Morgan, T.T.; Shanmugavelandy, S.S.; Kaiser, J.M.; McGovern, C.; Matters, G.L.; Smith, J.P.; Kester, M.; et al. Bioconjugation of calcium phosphosilicate composite nanoparticles for selective targeting of human breast and pancreatic cancers in vivo. ACS Nano 2010, 4, 1279-1287. [CrossRef] [PubMed]

20. Altinoglu, E.I.; Russin, T.J.; Kaiser, J.M.; Barth, B.M.; Eklund, P.C.; Kester, M.; Adair, J.H. Near-infrared emitting fluorophore-doped calcium phosphate nanoparticles for in vivo imaging of human breast cancer. ACS Nano 2008, 2, 2075-2084. [CrossRef] [PubMed]

21. Kester, M.; Heakal, Y.; Fox, T.; Sharma, A.; Robertson, G.P.; Morgan, T.T.; Altinoglu, E.I.; Tabakovic, A.; Parette, M.R.; Rouse, S.M.; et al. Calcium phosphate nanocomposite particles for in vitro imaging and encapsulated chemotherapeutic drug delivery to cancer cells. Nano Lett. 2008, 8, 4116-4121. [CrossRef] [PubMed]

22. Muddana, H.S.; Morgan, T.T.; Adair, J.H.; Butler, P.J. Photophysics of Cy3-encapsulated calcium phosphate nanoparticles. Nano Lett. 2009, 9, 1559-1566. [CrossRef] [PubMed]

23. Perkin, K.K.; Turner, J.L.; Wooley, K.L.; Mann, S. Fabrication of hybrid nanocapsules by calcium phosphate mineralization of shell cross-linked polymer micelles and nanocages. Nano Lett. 2005, 5, 1457-1461. [CrossRef] [PubMed]

24. Sugawara, A.; Yamane, S.; Akiyoshi, K. Nanogel-templated mineralization: Polymer-calcium phosphate hybrid nanomaterials. Macromol. Rapid Commun. 2006, 27, 441-446. [CrossRef]

25. Chen, Z.; Li, Z.; Lin, Y.; Yin, M.; Ren, J.; Qu, X. Biomineralization inspired surface engineering of nanocarriers for $\mathrm{pH}$-responsive, targeted drug delivery. Biomaterials 2013, 34, 1364-1371. [CrossRef] [PubMed]

26. Ding, Y.; Zhai, K.; Pei, P.; Lin, Y.; Ma, Y.; Zhu, H.; Shao, M.; Yang, X.; Tao, W. Encapsulation of cisplatin in a pegylated calcium phosphate nanoparticle (CPNP) for enhanced cytotoxicity to cancerous cells. J. Colloid Interface Sci. 2017, 493, 181-189. [CrossRef] [PubMed]

27. Han, H.S.; Lee, J.; Kim, H.R.; Chae, S.Y.; Kim, M.; Saravanakumar, G.; Yoon, H.Y.; You, D.G.; Ko, H.; Kim, K.; et al. Robust PEGylated hyaluronic acid nanoparticles as the carrier of doxorubicin: Mineralization and its effect on tumor targetability in vivo. J. Control. Release 2013, 168, 105-114. [CrossRef] [PubMed]

28. Min, K.H.; Lee, H.J.; Kim, K.; Kwon, I.C.; Jeong, S.Y.; Lee, S.C. The tumor accumulation and therapeutic efficacy of doxorubicin carried in calcium phosphate-reinforced polymer nanoparticles. Biomaterials 2012, 33, 5788-5797. [CrossRef] [PubMed]

29. Schmidt, H.; Ostafin, A. Liposome directed growth of calcium phosphate nanoshells. Adv. Mater. 2002, 14, 532-535. [CrossRef]

30. Rim, H.P.; Min, K.H.; Lee, H.J.; Jeong, S.Y.; Lee, S.C. pH-tunable calcium phosphate covered mesoporous silica nanocontainers for intracellular controlled release of guest drugs. Angew. Chem. Int. Ed. 2011, 50, 8853-8857. [CrossRef] [PubMed] 
31. Wang, X.Y.; Deng, Y.Q.; Li, S.Y.; Wang, G.C.; Qin, E.; Xu, X.R.; Tang, R.; Qin, C. Biomineralization-based virus shell-engineering: Towards neutralization escape and tropism expansion. Adv. Healthc. Mater. 2012, 1, 443-449. [CrossRef] [PubMed]

32. Wang, B.; Liu, P.; Jiang, W.; Pan, H.; Xu, X.; Tang, R. Yeast cells with an artificial mineral shell: Protection and modification of living cells by biomimetic mineralization. Angew. Chem. Int. Ed. 2008, 47, 3560-3564. [CrossRef] [PubMed]

33. Uekama, K.; Hirayama, F.; Irie, T. Cyclodextrin drug carrier systems. Chem. Rev. 1998, 98, $2045-2076$. [CrossRef] [PubMed]

34. Brewster, M.E.; Loftsson, T. Cyclodextrins as pharmaccutical solubilizers. Adv. Drug Deliv. Rev. 2007, 59, 645-666. [CrossRef] [PubMed]

35. Liu, B.; Li, C.X.; Cheng, Z.Y.; Hou, Z.Y.; Huang, S.S.; Lin, J. Functional nanomaterials for near-infrared-triggered cancer therapy. Biomater. Sci. 2016, 4, 890-909. [CrossRef] [PubMed]

36. Liu, X.M.; Lee, H.T.; Reinhardt, R.A.; Marky, L.A.; Wang, D. Novel biomineral-binding cyclodextrins for controlled drug delivery in the oral cavity. J. Control. Release 2007, 122, 54-62. [CrossRef] [PubMed]

37. Yu, T.; Ye, J.; Wang, Y. Synthesis and property of a novel calcium phosphate cement. J. Biomed. Mater. Res. Part B Appl. Biomater. 2009, 90, 745-751. [CrossRef] [PubMed]

38. Jacobsen, P.A.L.; Nielsen, J.L.; Juhl, M.V.; Theilgaard, N.; Larsen, K.L. Grafting cyclodextrins to calcium phosphate ceramics for biomedical applications. J. Incl. Phenom. Macrocycl. Chem. 2012, 72, 173-181. [CrossRef]

39. Viswanathan, K.; Vadivoo, V.S.; Raj, G.D. Rapid determination of hydrogen peroxide produced by Lactobacillus using enzyme coupled rhodamine isocyanide/calcium phosphate nanoparticles. Biosens. Bioelectron. 2014, 61, 200-208. [CrossRef] [PubMed]

40. Liu, Y.; Chen, Y.; Liu, S.X.; Guan, X.D.; Wada, T.; Inoue, Y. Unique fluorescence behavior of Rhodamine B upon inclusion complexation with novel bis(beta-cyclodextrin-6-yl) 2,2'-bipyridine-4,4'-dicarboxylate. Org. Lett. 2001, 3, 1657-1660. [CrossRef] [PubMed]

41. Ueno, Y.; Futagawa, H.; Takagi, Y.; Ueno, A.; Mizushima, Y. Drug-incorporating calcium carbonate nanoparticles for a new delivery system. J. Control. Release 2005, 103, 93-98. [CrossRef] [PubMed]

42. Agueros, M.; Zabaleta, V.; Espuelas, S.; Campanero, M.A.; Irache, J.M. Increased oral bioavailability of paclitaxel by its encapsulation through complex formation with cyclodextrins in poly(anhydride) nanoparticles. J. Control. Release 2010, 145, 2-8. [CrossRef] [PubMed]

43. Shaikh, M.V.; Kala, M.; Nivsarkar, M. Development and optimization of an ex vivo colloidal stability model for nanoformulations. AAPS PharmSciTech 2017, 18, 1288-1292. [CrossRef] [PubMed]

44. Yang, X.Z.; Du, X.J.; Liu, Y.; Zhu, Y.H.; Liu, Y.Z.; Li, Y.P.; Wang, J. Rational design of polyion complex nanoparticles to overcome cisplatin resistance in cancer therapy. Adv. Mater. 2014, 26, 931-936. [CrossRef] [PubMed]

45. Feng, X.R.; Ding, J.X.; Gref, R.; Chen, X.S. Poly( $\beta$-cyclodextrin)-mediated polylactide-cholesterol stereocomplex micelles for controlled drug delivery. Chin. J. Polym. Sci. 2017, 35, 693-699. [CrossRef]

(C) 2017 by the authors. Licensee MDPI, Basel, Switzerland. This article is an open access article distributed under the terms and conditions of the Creative Commons Attribution (CC BY) license (http://creativecommons.org/licenses/by/4.0/). 